\title{
Bone marrow metastasis of malignant melanoma in childhood arising within a congenital melanocytic nevus
}

\author{
Jana Volejnikovaa ${ }^{\mathrm{a}, \mathrm{b}}$, Viera Bajciovac, Lucie Sulovska ${ }^{\mathrm{a}}$, Marie Geierova ${ }^{\mathrm{d}}$, Eva Buriankova ${ }^{\mathrm{e}}$, Marie Jarosova ${ }^{f}$, Marian Hajduch ${ }^{\mathrm{b}}$, \\ Jaroslav Sterbac, Vladimir Mihala ${ }^{\mathrm{a}, \mathrm{b}}$
}

Background. Malignant melanoma in childhood is infrequent and can arise within congenital melanocytic nevi. Spread of malignant melanoma to the bone marrow, especially in children, is extremely rare.

Methods and Results. Reported is a case of a 5-year-old boy with a congenital large melanocytic nevus of the head and neck who presented with a short history of low back and leg pain, fever and cervical lymphadenopathy. Despite regular follow-up by a dermatologist and plastic surgeon and repeatedly negative histology of previous partial excisions, diffuse bone marrow infiltration with malignant melanoma was diagnosed. The primary site was identified in the post-excision area. The disease progressed rapidly on ipilimumab immunotherapy and led to death at four months from the diagnosis.

Conclusion. Surveillance is indispensable in children with a predisposition to melanoma and nonspecific symptoms such as bone pain, gait impairment or cytopenia, should always be taken into account.

Key words: bone marrow, childhood, congenital melanocytic nevus, malignant melanoma, metastasis

Received: October 29, 2015; Accepted with revision: March 23, 2016; Available online: April 1, 2016

http://dx.doi.org/10.5507/bp.2016.018

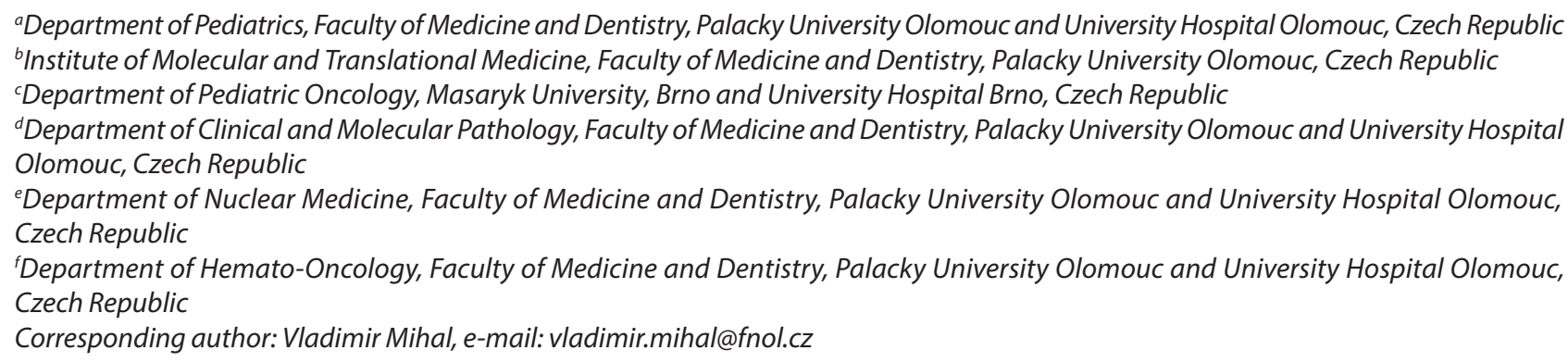

\section{INTRODUCTION}

In spite of recent diagnostic and therapeutic advances, metastatic malignant melanoma is a serious disease with poor prognosis in both children and adults. Malignant melanoma is rare in childhood, constituting approximately $3 \%$ of pediatric malignancies ${ }^{1}$. Its risk factors and clinical characteristics differ from those seen in melanoma in adults (e.g. different architectural and cytopathologic features; higher percentage of amelanotic and raised lesions, nodular histotype and thick lesions; more frequent primary melanomas of the head and neck; faster growth), with a background of a congenital melanocytic nevus being one of the predisposing factors ${ }^{2,3}$. Here we report a rare case of a 5-year-old boy with a large congenital melanocytic nevus of the head and neck who presented with malignant melanoma metastasizing to the bone marrow.

\section{CASE REPORT}

A 5-year-old boy, referred to our department by his general practitioner, had a 2-week history of pain in the lower extremities, especially in the shin area, gradually progressing over several days prior to his admission. The pain disturbed his sleep, responded only partially to nonsteroidal anti-inflammatory drugs and later spread to the lumbar and occipital areas. His parents also noticed gait impairment and inability to sit. One day before his admission, the boy presented to a pediatric emergency department with fever (up to $38.5^{\circ} \mathrm{C}$ ) and cervical lymphadenopathy. C-reactive protein and erythrocyte sedimentation rate tests gave negative results and ultrasound of the neck revealed round, hypoechoic nodes without liquefaction. Orthopedic examination showed limited lumbosacral flexion but unrestricted movement in the hips and other joints.

Since his four months of age, the boy had been followed up by a dermatologist and plastic surgeon for a large congenital melanocytic nevus of the head and neck extending across the entire right temporo-parieto-occipital region (Fig. 1). He underwent multiple plastic surgery procedures including four partial excisions, always with negative histology. The most recent histological examination performed 12 months earlier showed type I superficial congenital compound melanocytic nevus with maturation of nevi cells without atypia. The time since the last check-up by his plastic surgeon was six months. 
The boy was afebrile on admission. A large scar with an underlying palpable mass was found on the patient's scalp; his cervical (predominantly occipital) lymph nodes were palpable. The straight leg raise test was weakly positive. Neurological examination revealed neck stiffness (only in extension) and flaccid paralysis of both lower limbs. Laboratory tests found normal white blood cell count $\left(10.1 \times 10^{9} / \mathrm{L}\right)$ with mildly elevated neutrophils (65\%), a hemoglobin level and mean cell volume at the lower limits of normal ( $119 \mathrm{~g} / \mathrm{L}$ and $73 \mathrm{fL}$, respectively), normal platelet count (191 x 10 $/ \mathrm{L})$, increased D-dimers (9.2 nmol/L) and lactate dehydrogenase (12 $\mu \mathrm{kat} / \mathrm{L})$. Other laboratory values including inflammatory markers plus all performed swabs and serology results were negative. No pathology was found on x-ray of the chest and hips but straightening of the lumbar lordosis was seen on the lateral projection. Ultrasound examination of the neck confirmed the previous finding of enlarged round, hypoechoic lymph nodes up to $24 \mathrm{~mm}$ in diameter, without liquefaction. Abdominal ultrasound was normal except for a $2 \mathrm{~mm}$ wide band of fluid in the Douglas cavity. Because of suspected neuroinfection, lumbar puncture was performed early after admission, showing increased total cerebrospinal fluid $(\mathrm{CSF})$ protein $(1.4 \mathrm{~g} / \mathrm{L})$, albu$\min (1200 \mathrm{mg} / \mathrm{L}), \mathrm{IgM}(18.1 \mathrm{mg} / \mathrm{L})$ and CSF cell count (48 cells $/ \mu \mathrm{L}$ ). As the CSF was positive for anti-Borrelia species $\operatorname{IgM}(29 \mathrm{AU} / \mathrm{mL})$, intravenous antibiotic therapy was started (ceftriaxone $100 \mathrm{mg} / \mathrm{kg} /$ day).

Whole-body PET/CT was performed on the second day of hospitalization due to elevated lactate dehydrogenase and migrating pain in the lower extremities and spine. Multiple confluent foci of intense glucose hypermetabolism were detected in the extent corresponding to almost the entire active bone marrow, with maximum

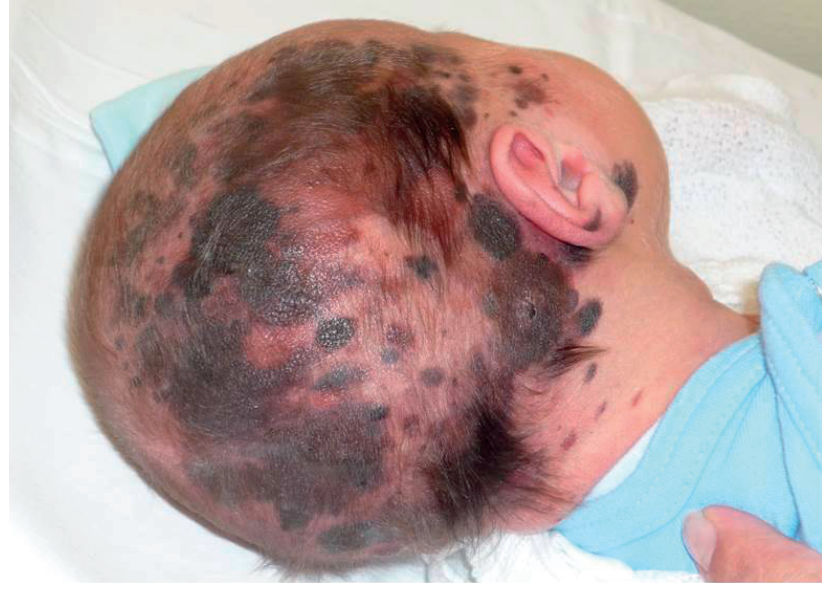

Fig. 1. Congenital large melanocytic nevus of the head and neck at 14 days of age.

changes in the spine, sternum, pelvis and both femurs. In contrast, neither the subcutaneous mass of the skull, cervical lymph nodes nor parenchymal organs showed increased glucose utilization (Fig. 2).

Subsequently, bone marrow aspiration and trephine biopsy were performed. Immunophenotyping revealed bone marrow infiltration with atypical cells of non-hematopoietic origin (strong expression of CD10, CD81, weak expression of CD56, CD117 and lack of CD45 and CD99) at a level of approximately $51 \%$. Trephine biopsy histology showed diffuse infiltration of the bone marrow by a monotonous population of large epithelioid tumor cells with large nuclei and high proliferative activity (Ki67 index of approximately 70\%). The cells expressed vimentin, S100 protein, melan-A and CD10. Interestingly,

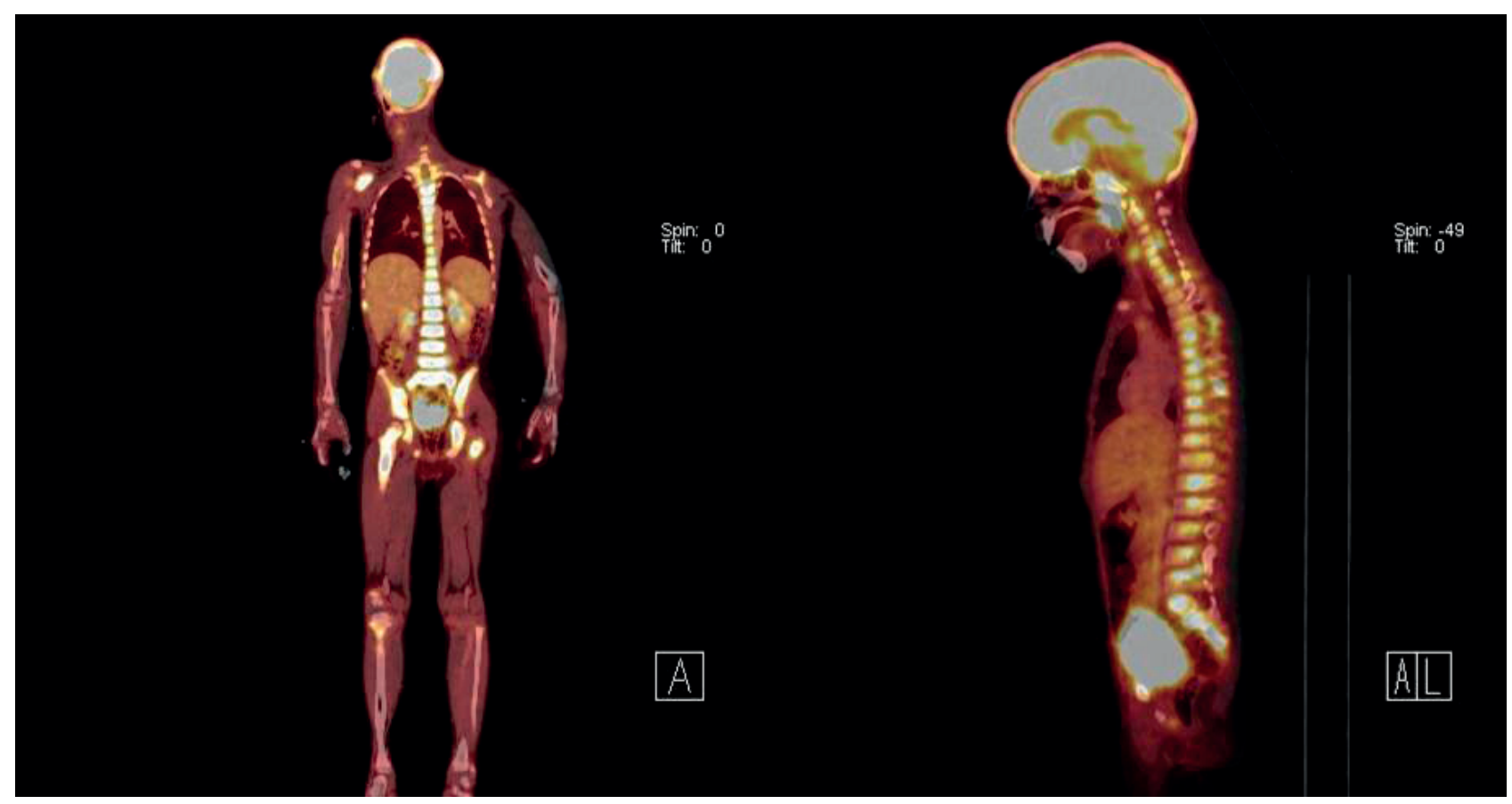

Fig. 2. Integrated whole-body PET/CT scan using ${ }^{18} \mathrm{~F}-\mathrm{FDG}$ : anteroposterior and lateral projections. Diffuse increase in FDG uptake in the bone marrow reflects malignant infiltration. 
$\mathbf{A}$

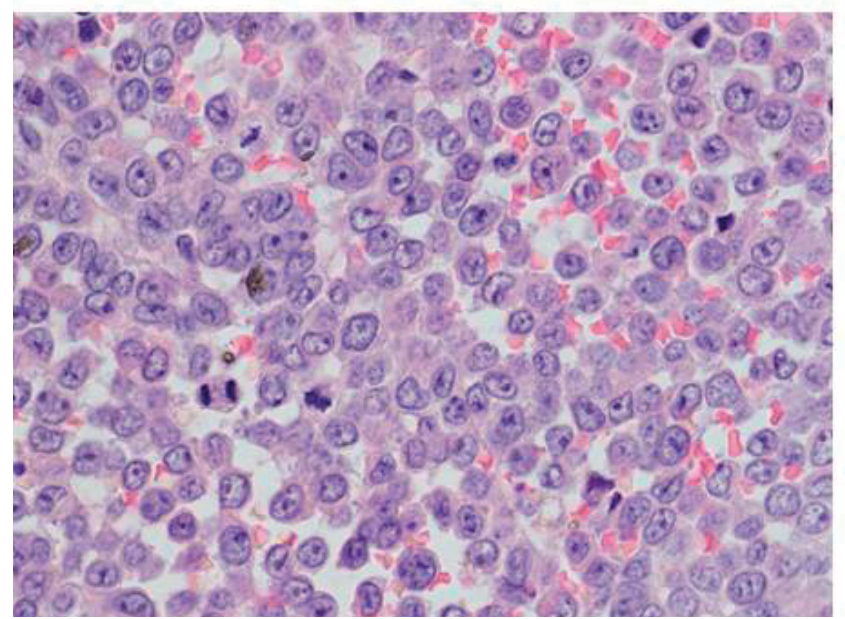

B

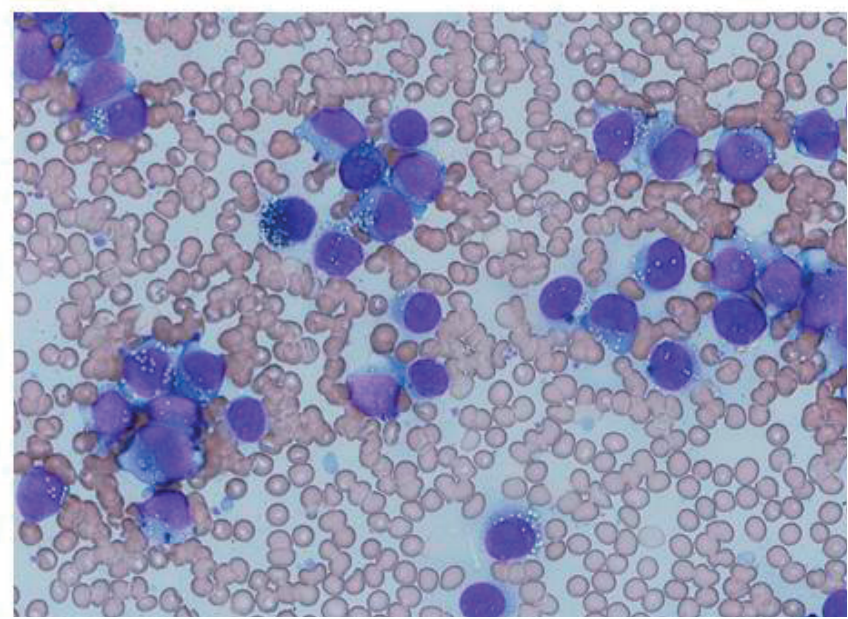

Fig. 3. Morphology of the bone marrow. (A) Trephine biopsy (magnification 400x, hematoxylin-eosin staining) and (B) bone marrow aspirate (magnification 400x, May-Grünwald-Giemsa staining) show diffuse infiltration with amelanotic cells with large nuclei, prominent nucleoli and vacuoles in the cytoplasm.

melanin was absent in the cytoplasm of malignant cells in the bone marrow aspirate and trephine biopsy (Fig. 3). Cytogenetic examination showed a complex karyotype of the malignant cells; subsequent FISH and mFISH identified three clones (Fig. 4).

The boy was referred to a pediatric oncology department where a subtotal resection of the tumor of the scalp was performed promptly, with the resection margins being positive. After completion of the initial work-up, the tumor was classified as nodular malignant melanoma with the primary lesion located on the head, Clark level 5, Breslow depth of $9 \mathrm{~mm}$, clinical stage IV - pT4a, N2b, M1c according to the AJCC classification, high risk with metastatic spread to the lymph nodes, bone marrow, liver, spleen and lumbar spine. The biological characteristics of the tumor included a high mitotic index, Ki-67 $35 \%$, positive angioinvasion, absence of ulceration, functional p53 (assessed by yeast functional assay) (ref. ${ }^{4}$ ) and positivity of $B R A F \mathrm{~V} 600 \mathrm{E}$ mutation. The level of infiltration with CD4+, CD8+, Treg and CD68+ cells was very low. A single-agent immunotherapy with the monoclonal antibody ipilimumab was started after confirmation of the diagnosis; four doses of ipilimumab were administered ( $3 \mathrm{mg} / \mathrm{kg}$, one course of 12 weeks) without serious side effects. Unfortunately, the disease progressed on treatment and orbital and spinal metastases developed. Laminectomy of L5 and S1 with subtotal resection of a spinal metastasis was required six weeks later due to a neurological impairment including paraparesis and leg pain. After four applications of ipilimumab, active treatment was stopped because of tumor progression and rapid clinical deterioration (anorexia, severe cachexia and poor performance status - Lansky score 10-20). At the parents' request, the therapy was continued with palliative metronomic chemotherapy (vinblastine weekly) plus symptomatic treatment. The patient died at home four months after the initial diagnosis of malignant melanoma.

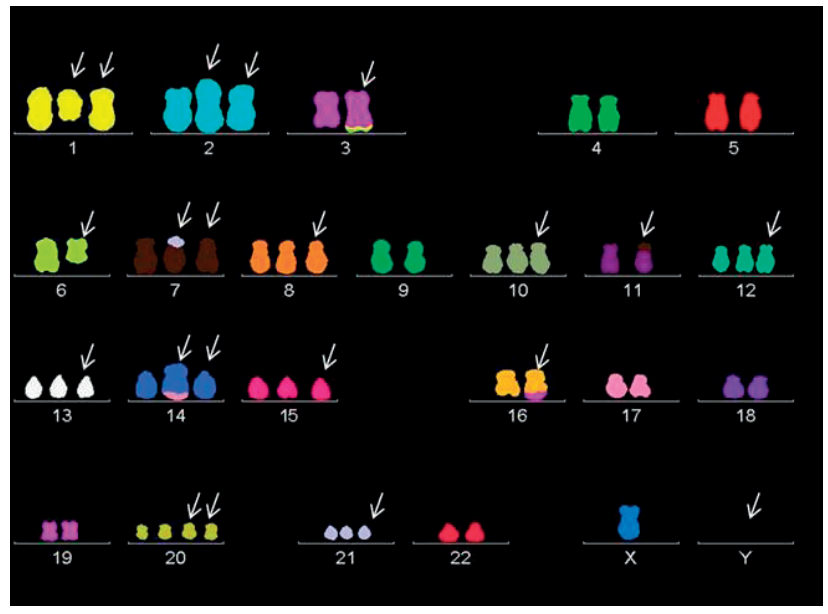

Fig. 4. Karyotype from the bone marrow aspirate. $59, X,-Y, d e l(1)(? q),+1, i(2)(p ? 11), \quad+2, \operatorname{der}(3) \mathrm{t}(3 ; 6)$ $(\mathrm{q} ? 28 ; \mathrm{q} ?),+7,+7,+8,+10, \operatorname{der}(11) \mathrm{t}(7 ; 11)(? ; ? \mathrm{p}),+12,+13, \mathrm{i}(14)$ $\mathrm{t}(14 ; 17)(\mathrm{q} ? ; ?),+14,+15, \operatorname{der}(16) \mathrm{t}(7 ; 16)(? ; ?), \operatorname{dup}(20)$ $(q ?),+20,+20,+20,+21[14] / 57, X,-Y, \operatorname{del}(1)(? q),+1, i(2)$ $(\mathrm{p} ? 11),+2, \operatorname{der}(3) \mathrm{t}(3 ; 6)(\mathrm{q} ? 28 ; \mathrm{q} ?), \operatorname{del}(6)(\mathrm{q} ?), \operatorname{der}(7) \mathrm{t}(7 ; 21)$ $(\mathrm{p} ? ; \mathrm{q} ?),+7,+8,+10, \operatorname{der}(11) \mathrm{t}(7 ; 11)(? ; ? \mathrm{p}),+12,+13, \mathrm{i}(14) \mathrm{t}(14 ; 17)$ (q?;?),+14,+15, der(16)t(16;19)(?;?),+20,+20,+21[4]/46,XY[2]. Clone with 57 chromosomes depicted.

\section{DISCUSSION}

Malignant melanoma is a rare entity in childhood and reports of its increasing long-term incidence trends have been recently challenged ${ }^{1,5}$. The known risk factors in children include genetic factors (genodermatoses such as xeroderma pigmentosum, dysplastic nevus syndrome, Werner syndrome, neurocutaneous melanosis) but also immunodeficiency, past cancer treatment and familial incidence of melanoma ${ }^{2,3}$. About $5-10 \%$ of large congenital melanocytic nevi give rise to malignant melanoma whose genomic characteristics and UV signature are different from those of conventional melanoma ${ }^{6,7}$. Approximately 
140 cases of metastatic malignant melanoma arising in large congenital melanocytic nevi have been reported so far $^{8-11}$. In a recent large study of pediatric malignant melanoma, only 8 of 443 patients developed melanoma on congenital nevi ${ }^{12}$. Furthermore, bone marrow metastasis in melanoma is exceptional, especially in childhood ${ }^{3,8}$.

Of note, absence of melanin in the cytoplasm of malignant cells in the bone marrow, as was seen in our patient, is also rare and allows an initial consideration of rhabdomyosarcoma. This fact may be important in the differential diagnosis because sporadic cases of rhabdomyosarcoma arising in a congenital melanocytic nevus have been reported ${ }^{13}$. However, immunophenotypic and cytogenetic findings in our patient were consistent with published data on malignant melanoma, including positivity of CD10 and CD117, complex karyotype changes with multiple polysomies reflecting the malignant potential of the tumor, including unbalanced translocations of chromosomes 3, 7, 11, 14 and 16, tetrasomy 20 and gain of chromosome 7 which has been associated with tumor progression $^{11,14-17}$.

Although surgery remains the first-line treatment for malignant melanoma, great progress has been made in the field of immunotherapy gradually replacing conventional chemotherapy. Apart from cytokines, monoclonal antibodies and dendritic cell vaccines, targeted "immune checkpoint blockade" therapy including inhibitors of cytotoxic T-lymphocyte antigen 4 (CTLA-4) (ipilimumab, tremelimumab), mitogen-activated protein kinase (MAPK) pathway inhibitors (vemurafenib, cobimetinib, dabrafenib and trametinib) and new immunotherapeutic agents such as programmed cell death 1 (PD-1) receptor and its ligand (PD-L1) blocking antibodies (nivolumab, pembrolizumab) have been introduced, igniting a revolution in the treatment of malignant melanoma since the FDA's approval of anti-CTLA-4 therapy in 2011 (ref. ${ }^{18-}$ $\left.{ }^{21}\right)$. Although combined inhibition (e.g. anti-CTLA-4 plus anti-PD-1) could represent the best available choice, the optimal sequence of targeted treatment is still undefined, especially in children. Ipilimumab monotherapy in our BRAF-positive patient was used because of his poor performance status and unavailability of a BRAF inhibitor at the time of diagnosis. A study of vemurafenib was started at our center more recently.

Long-term outcomes of malignant melanoma in childhood are generally favorable, but depend significantly on the tumor stage ${ }^{12}$. In a study by Lacoste et al., the mortality rate of malignant melanoma arising within large congenital melanocytic nevi was $60 \%$ (ref. ${ }^{11}$ ). Accordingly, in our patient with an extremely advanced disease, we were unsuccessful in reversing the rapid disease progression and death.

\section{CONCLUSION}

This is a unique report of malignant melanoma arising in a large congenital melanocytic nevus and metastasizing to the bone marrow in a 5-year-old boy. The question is whether the frequency of regular skin examinations is sufficient or should be increased in similar cases. We point to possible bone marrow involvement in children with predisposition to melanoma, where bone pain, gait impairment or cytopenia can mimic other neurologic or hematologic diseases.

Acknowledgement: Supported by a grant from the Czech Ministry of Education, Youth and Sports (NPU LO 1304).

Author contributions: VM: study design and supervision; $\mathrm{JV}$ : data collection, literature search and manuscript writing; VB, LS and JS: clinical management; MG: histopathologic examination; EB: PET/CT; MJ: cytogenetics; $\mathrm{MH}$ : molecular genetics. All co-authors have read the final manuscript within their respective areas of expertise and participated sufficiently in the study to take responsibility for it and accept its conclusions.

Conflict of interest statement: The authors state that there are no conflicts of interest regarding the publication of this article.

\section{REFERENCES}

1. Linabery $A M$, Ross JA. Trends in childhood cancer incidence in the U.S. (1992-2004). Cancer 2008;112(2):416-32.

2. Ceballos PI, Ruiz-Maldonado R, Mihm MC. Melanoma in children. N Engl J Med 1995;332(10):656-62.

3. Neuhold JC, Friesenhahn J, Gerdes N, Krengel S. Case reports of fatal or metastasizing melanoma in children and adolescents: a systematic analysis of the literature. Pediatr Dermatol 2015;32(1):13-22.

4. Flaman JM, Frebourg T, Moreau V, Charbonnier F, Martin C, Chappuis P, Sappino AP, Limacher IM, Bron L, Benhattar J. A simple p53 functional assay for screening cell lines, blood, and tumors. Proc Natl Acad Sci U S A 1995;92(9):3963-7.

5. Campbell LB, Kreicher KL, Gittleman HR, Strodtbeck K, BarnholtzSloan J, Bordeaux JS. Melanoma incidence in children and adolescents: decreasing trends in the United States. J Pediatr 2015;166(6):1505-13.

6. Alper JC, Holmes LB. The incidence and significance of birthmarks in a cohort of 4,641 newborns. Pediatr Dermatol 1983;1(1):58-68.

7. Pappo AS. Pediatric melanoma: the whole (genome) story. Am Soc Clin Oncol Educ Book 2014;e432-5.

8. Spiller SE, Hawkins DS, Finn LS, Sze RW, Sybert V. Metastatic malignant melanoma presenting as pancytopenia in a three-year-old boy. Pediatr Blood Cancer 2005;45(1):60-3.

9. Surrenti T, Diociaiuti A, Inserra A, Accinni A, Giraldi L, Callea F, El Hachem M. Melanoma in a 5-year-old child with a giant congenital melanocytic naevus. Acta Derm Venereol 2012;92(6):607-8.

10. Larsen $A K$, Jensen $M B$, Krag C. Long-term survival after metastatic childhood melanoma. Plast Reconstr Surg Glob Open 2014;2(6):e163.

11. Lacoste $C$, Avril MF, Frassati-Biaggi A, Dupin N, Chrétien-Marquet $B$, Mahé $E$, Bodemer $C$, Vergier $B$, de la Fouchardière A, Fraitag $S$. Malignant melanoma arising in patients with a large congenital melanocytic naevus: retrospective study of 10 cases with cytogenetic analysis. Acta Derm Venereol 2015;95(6):686-90.

12. Brecht IB, Garbe C, Gefeller O, Pfahlberg A, Bauer J, Eigentler TK, Offenmueller S, Schneider DT, Leiter U. 443 paediatric cases of malignant melanoma registered with the German Central Malignant Melanoma Registry between 1983 and 2011. Eur J Cancer 2015;51(7):861-8.

13. Hoang MP, Sinkre P, Albores-Saavedra J. Rhabdomyosarcoma arising in a congenital melanocytic nevus. Am J Dermatopathol 2002;24:269.

14. Dabas N, Byrnes DM, Rosa AM, Eller MS, Grichnik JM. Diagnostic role of chromosomal instability in melanoma. J Skin Cancer 2012;2012:914267. 
15. Udart M, Utikal J, Krähn GM, Peter RU. Chromosome 7 aneusomy. A marker for metastatic melanoma? Expression of the epidermal growth factor receptor gene and chromosome 7 aneusomy in nevi, primary malignant melanomas and metastases. Neoplasia 2001;3(3):245-54.

16. Barks JH, Thompson FH, Taetle R, Yang JM, Stone JF, Wymer JA, Khavari R, Guan XY, Trent JM, Pinkel D, Nelson MA. Increased chromosome 20 copy number detected by fluorescence in situ hybridization (FISH) in malignant melanoma. Genes Chromosomes Cancer 1997;19(4):278-85

17. Carless MA, Griffiths LR. Cytogenetics of melanoma and nonmelanoma skin cancer. Adv Exp Med Biol 2014;810:160-81.

18. Ascierto PA, Simeone E, Giannarelli D, Grimaldi AM, Romano A, Mozzillo N. Sequencing of BRAF inhibitors and ipilimumab in patients with metastatic melanoma: a possible algorithm for clinical use. J Transl Med 2012;10:107.
19. Olszanski AJ. Current and future roles of targeted therapy and immunotherapy in advanced melanoma. J Manag Care Spec Pharm 2014;20(4):346-56.

20. Robert C, Schachter J, Long GV, Arance A, Grob JJ, Mortier L, Daud A, Carlino MS, McNeil C, Lotem M, Larkin J, Lorigan P, Neyns B, Blank CU, Hamid O, Mateus C, Shapira-Frommer R, Kosh M, Zhou $\mathrm{H}$, Ibrahim N, Ebbinghaus S, Ribas A; KEYNOTE-006 investigators. Pembrolizumab versus ipilimumab in advanced melanoma. $\mathrm{N}$ Engl J Med 2015;372:2521-32.

21. Larkin J, Chiarion-Sileni V, Gonzalez R, Grob JJ, Cowey CL, Lao CD, Schadendorf D, Dummer R, Smylie M, Rutkowski P, Ferrucci PF, Hill A, Wagstaff J, Carlino MS, Haanen JB, Maio M, Marquez-Rodas I, McArthur GA, Ascierto PA, Long GV, Callahan MK, Postow MA, Grossmann K, Sznol M, Dreno B, Bastholt L, Yang A, Rollin LM, Horak C, Hodi FS, Wolchok JD. Combined nivolumab and ipilimumab or monotherapy in untreated melanoma. N Engl J Med 2015;373:23-34. 